\title{
La tierra y la sombra: cine háptico, violencia ambiental y desplazamiento forzado en Colombia ${ }^{1}$
}

\section{LAND AND SHADE: HAPTIC CINEMA, ENVIRONMENTAL VIOLENCE AND FORCED DISPLACEMENT IN COLOMBIA}

\section{LA TIERRA Y LA SOMBRA: CINEMA HÁPTICO, VIOLÊNCIA AMBIENTAL E DESLOCAMENTO FORCADO EM COLÔMBIA}

\author{
Carolina Sánchez *2 \\ cs1374@scarletmail.rutgers.edu
}

\begin{abstract}
Resumen
La película La tierra y la sombra (2015) de César Acevedo (Colombia, 1984) relata la historia de una familia que se niega a abandonar un territorio del que han sido desplazados todos los demás campesinos a causa de la imposición del monocultivo de caña de azúcar en el Valle del Cauca. Me ocupo de la pregunta ¿cuáles son las causas y consecuencias del desplazamiento forzado que presenta la película y qué tienen que ver con los territorios ecológicos? Argumento que a través de técnicas de cine háptico (Marks 2000), que usan la visión como un sentido del tacto, la película hace a los espectadores experimentar algunos efectos de la violencia ambiental que Rob Nixon (2011) llama violencia lenta. Considero que el film no sólo explora la migración campesina de un espacio rural a otro, sino también se ocupa del movimiento de fronteras políticas sobre territorios ecológicos causado por el extractivismo del monocultivo de caña de azúcar. Argumento que la violencia lenta se ejerce también contra seres y eco-sistemas no humanos y exploro cómo la película expone distintas precariedades y convierte al espectador en un testigo de este tipo de violencia política.
\end{abstract}

Palabras clave: cine háptico, desplazamiento forzado, extractivismo, monocultivo, violencia lenta

\section{Abstract}

The film Land and Shade (2015) by César Acevedo (Colombia, 1984) tells the story of

\footnotetext{
${ }^{1}$ Agradezco a Jorge Marcone, a Sofía Rosa y a Yeon-Soo Kim por sus valiosos comentarios a distintas versiones de este trabajo. Agradezco también a las compañeras del taller de escritura de la Plataforma Latinoamericana de Humanidades Ambientales por sus sugerencias y lecturas atentas.

$2 *$ Universidad de Rutgers, New Brunswick

Tekoporá ${ }^{\circledR}$. Centro Universitario de la Región Este. Universidad de la República (C) Sánchez. (2021)

Este es un artículo de Acceso Abierto distribuido bajo licencia Creative Commons (CC BY NC 4.0)
} 
a family that refuses to leave a territory from which all the other peasants have been displaced due to the imposition of the sugar cane monoculture in Valle del Cauca. The main question of this paper is what are the causes and consequences of forced displacement that the film presents and what do they have to do with ecological territories? I argue that through haptic film techniques (Marks 2000), which use vision as a sense of touch, the film makes viewers experience some of effects of the environmental violence that Rob Nixon (2011) calls slow violence. I argue the film not only explores the peasant migration from one rural space to another, but also deals with the movement of political borders on ecological territories caused by the extractivism of the sugar cane monoculture. I claim that slow violence is also exercised against non-human beings and ecosystems and I explore how the film exposes different types of precariousness and turns the viewer into a witness of this type of political violence.

Keywords: haptic cinema, forced displacement, extractivism, monoculture, slow violence.

\section{Resumo}

O filme La tierra y la sombra (2015), de César Acevedo (Colômbia, 1984), conta a história de uma família que se nega a deixar um território do qual todos os outros camponeses têm sido forçados a sair em razão da imposição da monocultura de cana-de-açúcar no estado de Valle del Cauca (Colômbia). Neste ensaio, parto das perguntas: quais são as causas e consequências do deslocamento forçado que apresenta o filme, e o que isso tem a ver com os territórios ecológicos? Meu argumento é que através das técnicas do cinema háptico (Marks, 2000), que usam a visão como um sentido do tato, o filme faz os espectadores experimentarem alguns efeitos da violência ambiental que Rob Nixon (2011) chama de violência lenta. Acredito que o filme não só explora a migração dos camponeses de um espaço rural para outro, mas também ocupa-se do movimento de fronteiras políticas sobre territórios ecológicos causado pelo extrativismo da monocultura de cana-de-açúcar. o meu argumento aponta à ideia de que a violência lenta se exerce também contra seres e ecossistemas não humanos e explora como o filme expõe as diversas precariedades e transforma o espectador numa testemunha deste tipo de violência política

Palavras-chave: cinema háptico, deslocamento forçado, extrativismo, monocultura, violência lenta 


\section{Introducción}

La película colombiana La tierra y la sombra (2015) de César Acevedo relata la historia de una familia que se niega a abandonar un territorio del que han sido desplazados todos los demás campesinos a causa de la imposición del monocultivo de caña de azúcar en el Valle del Cauca. La historia comienza cuando Alfonso regresa a su antigua casa doce años después de haberse desplazado. Allí viven su ex mujer Alicia, su nuera Esperanza, su nieto Manuel y su hijo, Gerardo, cuya enfermedad es el motivo del regreso de Alfonso. Gerardo se ahoga a causa de la contaminación y las cenizas causadas por la quema de caña; y la subsistencia de la familia, que trabaja en la plantación, está en peligro. Durante la película, los miembros de la familia se debaten sobre si es mejor desplazarse para sobrevivir. Su casa es la última que queda en pie en el monocultivo. Constantemente en el film se alternan las tomas del interior oscuro de la casa, que se ha convertido en una celda donde no se pueden abrir las puertas ni ventanas a causa de la contaminación, y el exterior formado por cañaverales iluminados y altos como rejas, organizados casi militarmente, que acechan la casa por todos los costados como si se tratara de una cárcel verde. El aspecto que más llama la atención de la película es este gesto constante de filmar paisajes, y esto me lleva a preguntarme ¿por qué una película sobre el desplazamiento forzado en Colombia se enfoca en retratar los paisajes? ¿Qué significa este continuo alternar entre grabar los paisajes, la casa situada en los cañaverales y el día a día de la familia que allí vive, amenazada por las precarias condiciones de trabajo que le impone una multinacional azucarera?

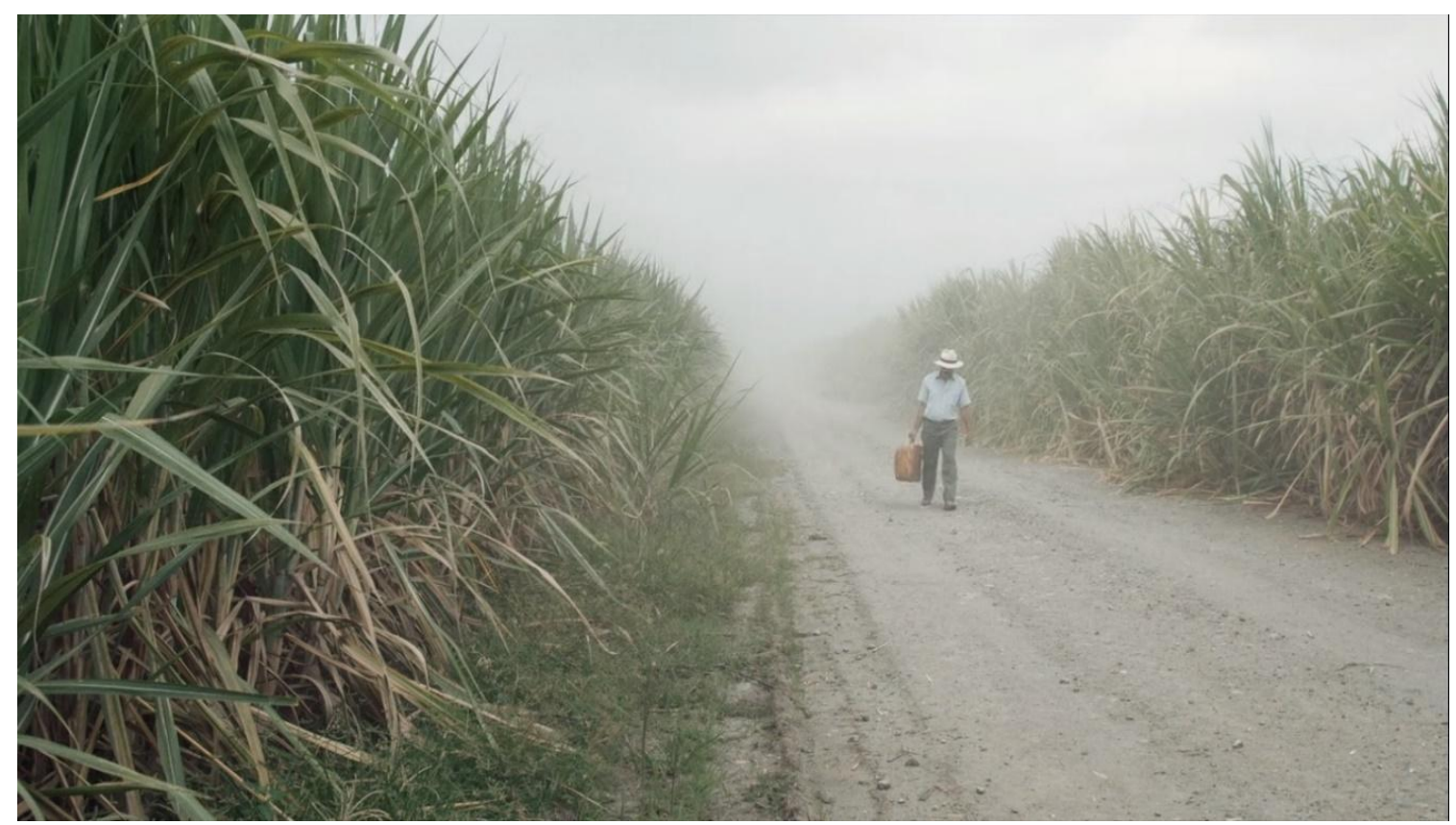

Figura 1. Doce años después de haberse desplazado, Alfonso regresa a su casa para cuidar a su hijo enfermo.

La pregunta principal de este trabajo es: ¿cuáles son las causas y condiciones del desplazamiento forzado en Colombia que presenta la película, y qué tienen que ver con los territorios ecológicos? 0 , en otras palabras, ¿qué tipos 
de migración forzada dentro de las fronteras nacionales muestra la película y cómo se relacionan con el monocultivo de caña de azúcar? Este texto examina las maneras en que la película La tierra y la sombra (2015), valiéndose de técnicas de cine háptico (Marks, 2000), presenta la cuestión del desplazamiento o la migración forzada en los territorios colombianos en la época contemporánea desde dos perspectivas complementarias. Mi tesis es que la película no sólo explora el desplazamiento de las personas, sino también considera el movimiento de fronteras políticas sobre territorios socio-ecológicos causado por el extractivismo ${ }^{3}$ del monocultivo. Estos dos tipos de desplazamiento generados por el extractivismo, el de personas y el de fronteras, son violencias políticas y ecológicas relacionables a partir del concepto de "violencia lenta" de Rob Nixon (2011), que da cuenta de la forma de operar del daño ambiental. De manera más específica, considero que la violencia lenta es una de las principales causas del desplazamiento de los campesinos, puesto que el monocultivo afecta de manera directa sus condiciones de vida y sus agencias. La violencia lenta es un tipo de violencia político-ecológica que genera una serie de daños progresivos que van desde la precariedad hasta el arruinamiento. Argumento que la violencia lenta se ejerce también contra seres y eco-sistemas no humanos, generando un proceso de arruinamiento, según el desarrollo de este último concepto propuesto por Ann Stoler (2013).

La película acerca al espectador a la violencia que sufren los desplazados y el territorio a partir del uso de ciertas técnicas de cine que son fundamentales a la luz de la recepción de la obra y el posicionamiento del espectador. El film es como un gran dispositivo de visión que genera una manera alterna de acceder a los problemas de la relación monocultivo-desplazamiento, y se distancia de los imaginarios nacionales que están fuertemente instaurados en la opinión pública, que convierten los paisajes en tarjetas postales dentro de un proyecto de país-marca para atraer el turismo y la intervención extranjera como formas de extractivismo (Ospina, 2017, p. 249). En contraste, la película de Acevedo hace una crítica a estos proyectos político-económicos al mostrar el paisaje como una cárcel verde, como un laberinto que asfixia al espectador, en el que las plantas se han convertido en rehenes de una formación militar. En la película, el espectador no domina el paisaje ni este se domestica o exotiza para las audiencias urbanas. Inmersos en los juegos multisensoriales que nos propone el film es difícil identificar qué pasa; no se trata de una romantización o mistificación del paisaje, sino que hay un peligro latente.

Los juegos multisensoriales del cine háptico no usan la visión para simplificar y dominar lo observado, sino que nos permiten percibir aquello para lo que nuestra visión no está entrenada; dirigen nuestra atención hacia lo que vemos borroso, ya sea porque no sabemos qué es o se hace difícil de identificar. Con estos gestos hápticos, a través de distintas experiencias sensibles, la película nos permite presentir y empezar a distinguir los grandes daños ecológicos que acechan a los personajes, y se van expandiendo como una sombra sobre el medio ambiente, dentro y fuera del mundo de la película. Las tomas panorámicas del paisaje a plena

\footnotetext{
3 Por extractivismo entiendo la extracción y eliminación masiva de recursos naturales para alimentar el capitalismo global.
} 
luz nos lastiman los ojos y nos desorientan. Casi que la luz nos corta con su filo, así como la escena en la que una hoja de caña le corta la mano de Alfonso, uno de los campesinos desplazados en la película.

María Ospina (2011) y Camilo Malagón (2020) han reflexionado sobre la película en relación con los problemas ambientales y la han situado en el contexto del cine colombiano. Ospina, señala que la La tierra y la sombra hace parte del "giro rural", que se caracteriza por cierta hibridez entre los géneros de testimonio, documental y ficción y se ha desarrollado en la última década del cine colombiano a partir de la política sobre cine emitida en 2003. Las películas de esta corriente prestan atención a la creciente militarización del país, por parte de ejércitos legales e ilegales, el fenómeno del desplazamiento generado por la ausencia de reforma agraria, la ausencia de bienestar territorial para los campesinos y las reconfiguraciones territoriales que imponen los distintos proyectos extractivos que se siguen incrementando en el país (Ospina, 2017, p. 248). Películas como la Sirga (2016), el Vuelco del cangrejo (2010) y El abrazo de la serpiente (2016) hacen parte de esta corriente que representa violencias ambientales, cuya naturaleza es difícil de percibir. Esto es a diferencia de películas como La vendedora de rosas (1998) de Víctor Gaviria o La estrategia del caracol (1993) de Sergio Cabrera, que se concentran en los espacios de las ciudades y representan las violencias de maneras más explícitas.

No percibir la violencia lenta de carácter ambiental que señala la película es un problema político fundamental para Colombia, porque esta violencia es una de las causas estructurales del conflicto armado y político del país. Las dificultades de reconocer la violencia ecológica, como señala Nixon, están en que ocurre en lapsos más largos de tiempo en comparación con otras violencias políticas más explícitas como disparos, bombas o asesinatos. Por su parte, la violencia lenta obedece a cadenas causales más complejas, como tratados de libre comercio, alineación entre Estados y corporaciones en distintas geografías, precarización paulatina de condiciones laborales durante varias generaciones, deforestación o extracción de recursos naturales en lugares considerados "lejanos" o que son invisibilizados por el Estado, el mercado, los imaginarios culturales y la opinión pública. ${ }^{5}$ Asimismo, es importante recordar que durante la filmación y estreno de la película, en Colombia se estaban negociando los acuerdos de paz de la Habana firmados en 2016. El primer punto del documento final de este proceso político es abogar por la paz territorial, y solucionar los problemas de la propiedad de la tierra, que están estrechamente relacionados con el desplazamiento y el extractivismo. Desde la firma de los acuerdos de paz hasta mediados del año 2020, 971 líderes sociales han sido asesinados en Colombia (Martinez, 2020). Según la misma fuente, la mayoría

\footnotetext{
${ }^{4}$ Esta distinción me genera dudas, porque las ciudades también tienen espacios rurales.

${ }^{5}$ Un ejemplo específico del tipo de violencia lenta que trabaja la película, y la opinión pública colombiana falla en reconocer de manera directa como causa de la guerra civil, es el escándalo de corrupción de Agro Ingreso Seguro (AIS) que estalló en 2009. AIS fue una iniciativa del Estado colombiano diseñada para ofrecer préstamos a pequeños agricultores para inversión y desarrollo. Sin embargo, los subsidios y las tierras fueron asignados a latifundistas y corporaciones privadas que siembran monocultivos de palma de cera para exportar al mercado internacional y financian campañas presidenciales (Malagón, 2020, p. 36).
} 
de estas personas son del sector campesino, y un 70\% de los asesinatos se dieron por conflictos agrarios por tierras, territorios y recursos naturales.

La tierra y la sombra u técnicas de cine háptico para presentar los daños de la violencia lenta y hacer que los espectadores experimenten algunos de sus peligros mientras ven el film. La palabra "háptico" alude al sentido del tacto $\mathrm{y}$ significa tocar; estar en contacto con. El cine háptico, como señala Laura Marks (2000), se propone representar sentidos corporales como el tacto, el olfato o el gusto, que el cine técnicamente no puede representar. Esta exploración de los límites del medio audiovisual implica dos experiencias centrales para el espectador. Por una parte, las técnicas hápticas exploran formas alternas de visualidad que se oponen a la primacía de lo óptico. Lo óptico es un uso de la mirada que implica distancia, juicio y cierto poder sobre lo observado, mientras que el uso háptico de la visualidad implica usar el ojo como si fuera el tacto que va recorriendo la superficie de la pantalla tanteando, y este contacto implica cierta inmediatez (el tacto es un sentido que no se puede experimentar desde la distancia) y una experiencia en la que la memoria corporal y los distintos cruces y sinestesias entre los sentidos son necesarios para reconocer lo que se está experimentando (Marks, 2000, pp.128-133).

En la película, en las escenas al interior de la casa, Acevedo se vale del movimiento de la cámara y el uso de la luz para hacernos experimentar hápticamente. La casa está siempre a oscuras y no podemos distinguir los contornos de las cosas, entonces recorremos las estancias tanteando con la mirada, mientras intentamos identificar qué pasa siguiendo los movimientos lentos de la cámara y observando los cuerpos de los personajes que casi no hablan. Otro ejemplo es cuando Esperanza se ducha luego de una jornada de trabajo en los cañaverales. Escuchamos el agua caer y buscamos en la pantalla el origen del sonido. A partir de close-ups la cámara se concentra en distintas partes de su cuerpo mientras vemos la tierra resbalar con el agua sobre la piel del personaje y uno de sus pies restriega el otro para sacarse la tierra. ${ }^{6}$ Otros elementos que construyen el universo háptico de la película son las texturas de las cortinas que vuelan y la presencia de polvo y ceniza que hacen alusión al tacto y al olfato.

\footnotetext{
${ }^{6}$ Otros ejemplos de técnicas hápticas en el cine son grabar telas y texturas, rasgar la imagen y usar la pantalla como un papel sobre el que se escribe.
} 


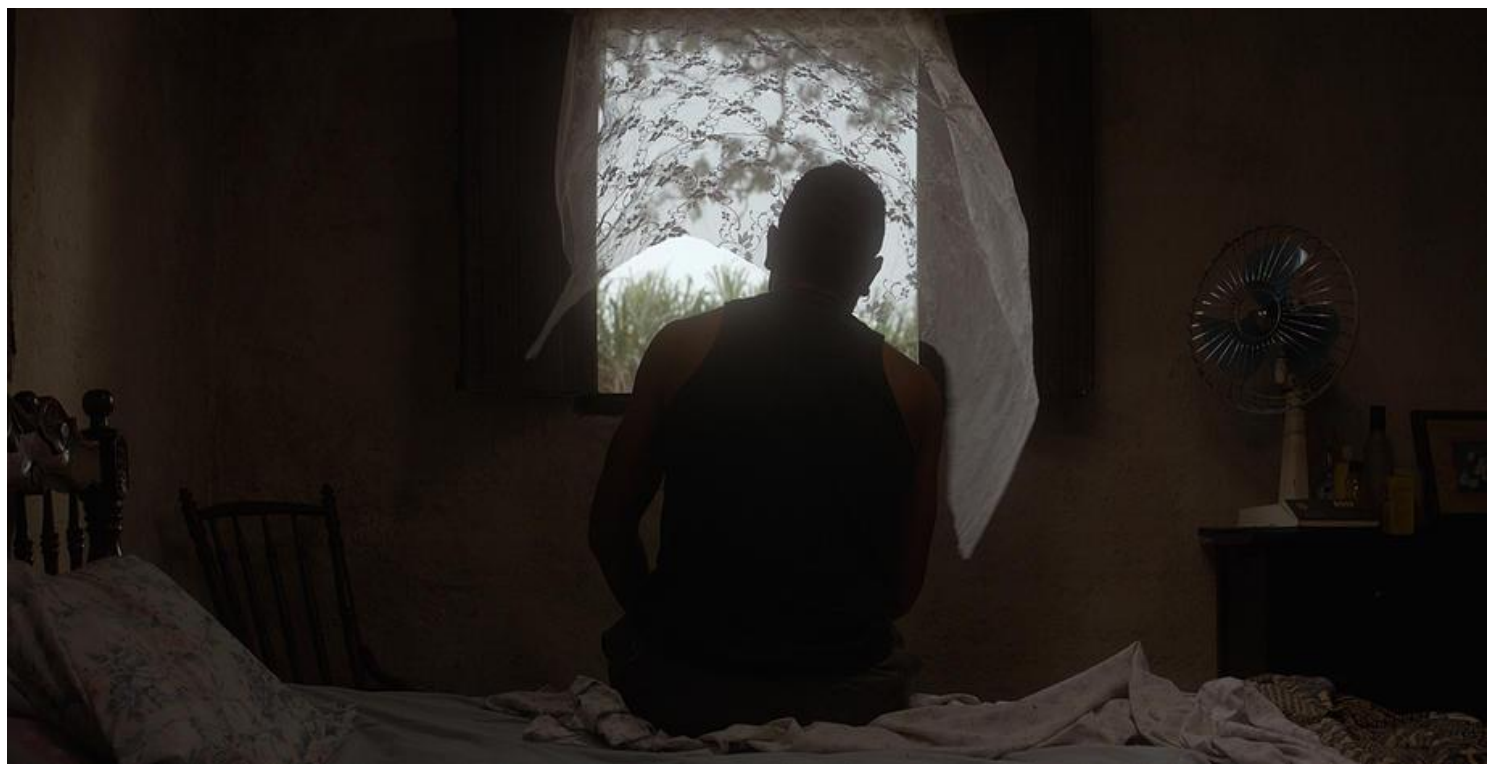

Figura 2. Gerardo de espaldas. No han diagnosticado su enfermedad, pero su cuerpo la siente.

La segunda experiencia que permite el cine háptico, y que será clave para la interpretación de la película que propongo, es su capacidad de expandir los límites de los sentidos y percibir en cierta medida lo que está al otro lado de ese límite. Lo háptico no alude directamente a lo táctil, sino que señala la experiencia del tacto que no puede representar directamente, a través de una experiencia multisensorial (sonido, imagen, movimiento) y de la activación de la memoria corporal. A partir de sus límites alude al otro lado de ellos, y nuestra memoria corporal "llena el hueco" identificando esas experiencias sensibles. De esta manera, el cine nos da cierta experiencia oblicua de ellas. Para mi análisis de La tierra y la sombra esto significa dos cosas. Primero, que podemos tener cierta experiencia de las condiciones de la violencia ambiental que sufren los campesinos y que los lleva a desplazarse. La película nos permite entrar en contacto con realidades íntimas y experimentarlas de manera oblicua. Este experimentar con ellos se opone a experimentar por ellos. No tenemos una experiencia óptica distante que juzga solo en tercera persona, ni una experiencia en primera persona de las condiciones del desplazamiento, pero tenemos una experiencia en primera persona del vértigo y el daño de la violencia ambiental y el desplazamiento a partir de la experiencia de ver la película y percibir en algún grado la violencia lenta. Segundo, el ir más allá de los sentidos que permite el cine háptico nos permite percibir "la génesis de cuerpos desconocidos" (Deleuze citado en Marks, 2000, p. 128). Estos cuerpos son los de las cañas, el samán y los pájaros de la película que, como mostraré más adelante, son agentes políticos.

\section{Causas del desplazamiento forzado: extractivismo, violencia lenta $y$ arruinamiento}

En la película, el cuerpo de Gerardo, a través de su enfermedad, encarna la violencia lenta y el arruinamiento que sufre también la tierra. Gerardo está relegado a una cama debido a una enfermedad respiratoria que los médicos se 
niegan a diagnosticar, y está relacionada con las quemas de los monocultivos de caña que cercan su casa. Esta dificultad de diagnóstico es propia de la violencia lenta de los problemas ambientales que, como señala Nixon, se desarrollan en lapsos largos de tiempo y con impactos solo gradualmente visibles, pero devastadores. La película se vale de estrategias sensoriales para hacernos percibir la violencia lenta que representa la enfermedad del personaje: la casa siempre está oscura porque las ventanas no se pueden abrir para que no entre la contaminación, se escucha a Gerardo respirar dificultosamente y en los peores días su pecho silba. Ha perdido la capacidad de trabajar y casi no se puede mover. Mientras tanto, su madre Alicia y su esposa Esperanza trabajan sin descanso sin obtener los recursos necesarios para que la familia subsista: son las únicas dos mujeres que cortan caña junto con los antiguos compañeros de trabajo de Gerardo, se ocupan de cuidarlo a él y a su hijo Manuel de seis años, así como de cocinar y mantener la casa. Sin embargo, todo este trabajo no basta y la sentencia de muerte que carga la violencia lenta se hace tangible en la película cuando Gerardo muere.

Como señala Rob Nixon (2011), la violencia lenta propia de los conflictos ambientales ocurre fuera del radar y los parámetros de lo que solemos reconocer como violencia: no es un único evento, carece de espectacularidad y no es explosiva, ni instantánea, ni sensacionalista, sino que ocurre gradualmente: se compone de calamidades y catástrofes con efectos a largo plazo, que se dispersan en el tiempo y en el espacio (Nixon, 2011, pp. 2-10). Algunos ejemplos de esta violencia que se pueden identificar en la película son la contaminación del aire generada por la quema de las cañas secas, y la destrucción de ecosistemas diversos y sostenibles que evidencia la imposición del monocultivo. Este tipo de violencia genera daños e impactos planetarios a escalas exponenciales que tienen efectos irreversibles para la salud del medio ambiente y los humanos, como han señalado varias agencias ambientales.

La violencia lenta que muestra la película La tierra y la sombra implica movimientos y cambios que son difíciles de percibir y comprende procesos que tienen varias causas complejas que ocurren simultáneamente o se desencadenan en distintas direcciones (Nixon, 2011, p. 11). En la película, los siguientes cinco procesos causados por el daño ambiental ocurren al tiempo y se propagan como un implacable goteo que se va acumulando y se hace cada vez más terrible. En primer lugar, Gerardo se está muriendo de una enfermedad causada por la contaminación ambiental que los médicos se niegan a diagnosticar. En segundo lugar, las condiciones laborales en los cañaverales empeoran y su madre y su esposa primero no reciben la paga y luego son despedidas sin razón aparente. En tercer lugar, no hay acceso a la salud ni a otros derechos como la posibilidad de un trabajo para que la familia sobreviva. En cuarto lugar, hay una ausencia y olvido deliberados por parte del Estado; no hay ante quién poner ninguna denuncia ni hacer valer ningún derecho porque se trata de una región excluida de la visibilidad nacional, de la esfera pública y de las condiciones que permiten ejercer la ciudadanía. Así, muy pocas personas saben lo que está pasando y se hace más difícil ayudar a los afectados por medio de decisiones políticas, y el cumplimiento de derechos humanos y ambientales. Y en quinto lugar, esta serie de conflictos se extiende entre varias generaciones de la familia generando peleas y abandonos entre los familiares y el territorio, lo cual significa una disolución de la comunidad política y 
de las condiciones de convivencia y sobrevivencia.

Recientemente, Camilo Malagón (2020) también propuso una lectura de las películas La tierra y la sombra y Chocó, a la luz del concepto de violencia lenta de Rob Nixon. Según Malagón, en estas obras hay una articulación entre la violencia lenta y la violencia política a partir de los siguientes seis elementos: "preocupación ambiental, conflicto familiar, preocupación por los niños, problemas con los sentidos de lugar y hogar, precariedad laboral y resistencia social y / o política" (p. 30). ${ }^{7}$ Coincido con Malagón, pero considero que la violencia lenta, en especial en el caso del desplazamiento colombiano del que se ocupa la película, tiene una cobertura más amplia. Esto es, la violencia lenta genera un segundo tipo de desplazamiento que consiste en el movimiento de fronteras hasta transformar los territorios en lugares inhabitables, como es el caso del monocultivo de caña de azúcar. En palabras de Nixon:

La comunidad se niega a irse pero, a medida que su mundo se ve socavado, efectivamente se convierte en una comunidad de refugiados en el que era su lugar. [Estas] no son solo [...] comunidades que son reubicadas involuntariamente y (a menudo militarmente) en entornos menos hospitalarios, sino aquellas afectadas por lo que llamo desplazamiento sin moverse. En otras palabras, quiero proponer una noción más radical de desplazamiento, una que, en lugar de referirse únicamente al movimiento de personas fuera de sus lugares de pertenencia, se refiere más bien a la pérdida de la tierra y los recursos bajo sus pies, una pérdida que deja comunidades desamparadas en un lugar despojado de las características que antes lo hacían habitable. (Nixon, 2011, p. 19) ${ }^{8}$

Mi tesis de que en el caso colombiano la violencia lenta incluye también el desplazamiento de fronteras, se alinea con el análisis de Nixon, en la medida que considero que el movimiento de fronteras socio-ecológicas por parte de corporaciones extractivistas con el apoyo de los Estados nacionales, es un tipo de desplazamiento. Uno que no requiere de viajes y movimiento de personas a otros lugares, como condición de la pérdida del territorio. Así, a pesar de que los miembros de la familia no se desplacen pierden la tierra, porque la violencia lenta que causa el extractivismo la arruina y genera una serie de precariedades que impiden la supervivencia en el territorio. La imposición del monocultivo transforma el paisaje hasta volverlo inhabitable, hasta volverlo tóxico y un agente

\footnotetext{
7 Todas las traducciones del inglés de este artículo son propios. Asimismo, ofrezco también las citas originales: "environmental concern, filial conflict, concern for children, sense of place and home, labor precarity and social and/or political resistance".

8 "The community refuses to move but, as its world is undermined, effectively becomes a community of refugees in place. [Those] are not just [...] communities that are involuntarily and (and often militarily) relocated to less hospitable environs, but also those affected by what I call displacement without moving. In other words, I want to propose a more radical notion of displacement, one that, instead of referring solely to the movement of people from their places of belonging, refers rather to the loss of the land and resources beneath them, a loss that leaves communities stranded in a place stripped of the very characteristics that made it inhabitable" (Nixon, 2011, p. 19).
} 
que mata a quienes lo habitan.

Mi acercamiento añade otro elemento a la discusión y es que la violencia lenta es un tipo específico de violencia política en la medida que afecta a agentes humanos y no humanos. Considero que los agentes naturales como las cañas no son solo recursos, como señala Nixon en la cita anterior. Sino que son agentes políticos que también son amenazados por la violencia lenta que extermina sus condiciones de vida y sus cuerpos. Esto es, las plantas de caña, los pájaros, y el samán, entre otros agentes no humanos, son agentes políticos (o actantes) no solo en la medida que están vivos biológicamente, sino porque tienen un rol activo en la convivencia y vida sostenible en los territorios; hacen parte de la comunidad en la que también participa la familia campesina que retrata la película, y de su bienestar y el cuidado de sus formas de vida depende la supervivencia y el bienestar de los agentes humanos y no humanos a nivel local y global.

Me ocuparé ahora de cómo la película representa las causas de la violencia lenta a partir de las interacciones entre los agentes humanos, los actantes y el paisaje. Parados frente a la casa rodeada de un paisaje en llamas, en una escena de la película que tiene un ambiente apocalíptico, Esperanza y su hijo Manuel, Alicia y Alfonso observan el carro que se lleva a Gerardo muerto, desaparecer por un camino lleno de ceniza. No es de noche, pero el ambiente está oscuro a causa del humo que sale de los cultivos. Esta es la única escena de la película en la que la luz natural no ilumina los cañaverales, sino que, por el contrario, una iluminación de tono bajo crea un ambiente sombrío. Esta escena sugiere una continuidad entre la devastación de la casa y de la familia que significa la muerte de Gerardo y la devastación que sufre la tierra y el paisaje que rodea la casa. No es casual que justo el día que se llevan el cuerpo de Gerardo, los alrededores de su casa estén en llamas: la sensación de encierro y cárcel no atañe solo al interior de la casa y quienes viven en ella, sino al territorio y los cañaverales encarcelados en el monocultivo. 


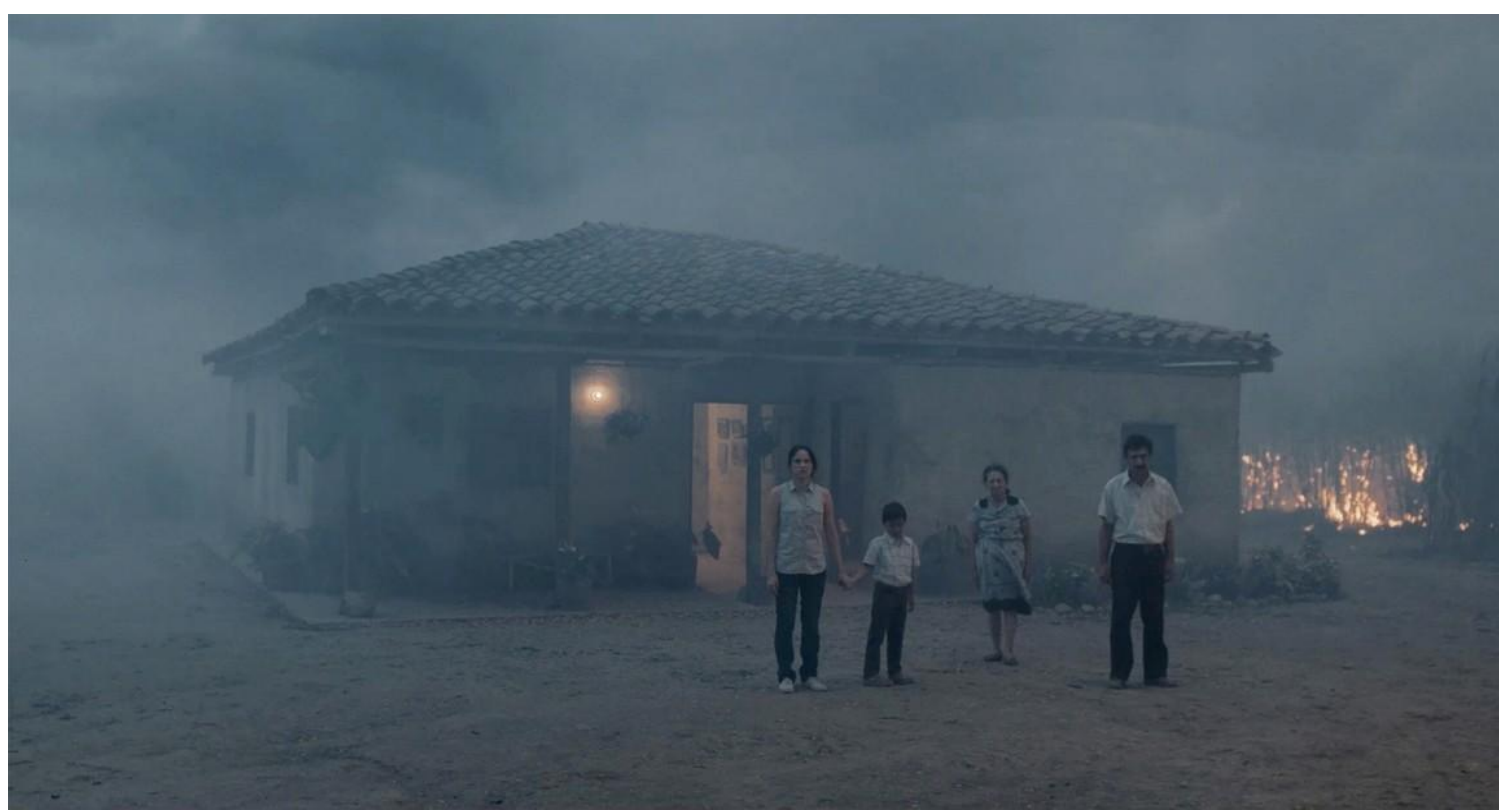

Figura 3. Esperanza, Manuel, Alicia y Alfonso observan el carro que se lleva el cuerpo de Gerardo

La secuencia de la película en la que se llevan el cuerpo de Gerardo enfrenta al espectador con la pregunta sobre qué significan la tierra y la sombra y cómo se relacionan. La cámara se adentra en los cañaverales a través de un movimiento de travelling. El sonido diegético del fuego quemando las plantas se intensifica, como si las cañas gritaran. El viento silba fuerte. Estamos ante la escena con más elementos hápticos de la película. Las plantas se mueven con violencia como intentando resistir su exterminio. La impresión de observar las superficies de las plantas en movimiento, su piel lisa, se entrecruza con los sonidos que hacen el viento y el fuego al tocarlas, evocando su textura y creando un efecto sinestésico. Vemos las llamas quemando el cultivo de caña que produce humo negro, rojo y cenizas. Este rojo sugiere que la tierra sangra, como consecuencia de la batalla que libra. La tierra y la sombra son los personajes principales de la película. La tierra es el territorio ecológico-político en el que viven distintos actantes cuyas condiciones de vida, como Gerardo, están siendo violentados por la sombra. La sombra es el extractivismo de caña de azúcar, el monocultivo que extermina la diversidad que permite la sostenibilidad y mata a la personas y agentes naturales. 


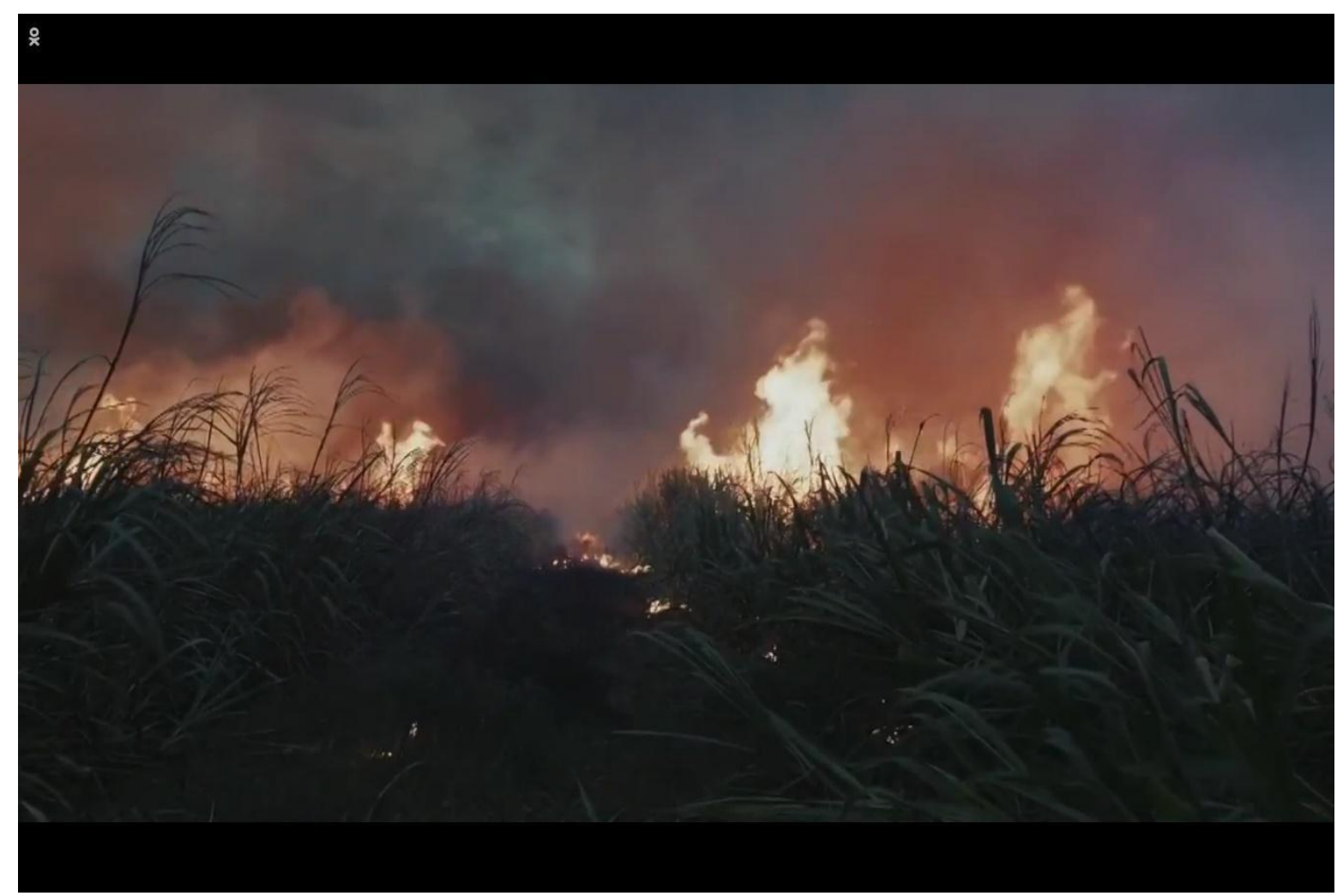

Figura 4. El fuego y la contaminación se expanden por el paisaje mientras las cañas intentan resistir su propio exterminio.

Durante toda la película, Acevedo pone a los paisajes y a los personajes en contacto y sugiere que son superficies o pieles continuas, cuyas vidas son interdependientes. Debido a que los agentes ecológicos, como las cañas, tienen una perspectiva como nos lo hace experimentar la posición de la cámara, los espectadores podemos adjudicarles agencia a estos seres no humanos. La percepción de estos agentes que nos permiten las técnicas hápticas de la película es "la génesis de cuerpos desconocidos" (Deleuze citado en Marks, 2020, p. 127) mencionada más arriba. La película nos ha hecho ver que los cañaverales no son simplemente el "escenario" pasivo en el que ocurre la historia, sino que son los personajes de la película. Una de las maneras en las que la película muestra la identificación entre campesinos y cañas de azúcar es a través de la puesta en escena de las mujeres trabajando en los cañaverales. Los uniformes de trabajo de Alicia y Esperanza tienen el mismo color de la caña seca que ellas cortan; tanto las vidas de las mujeres como las de las cañas están siendo segadas durante la película. 


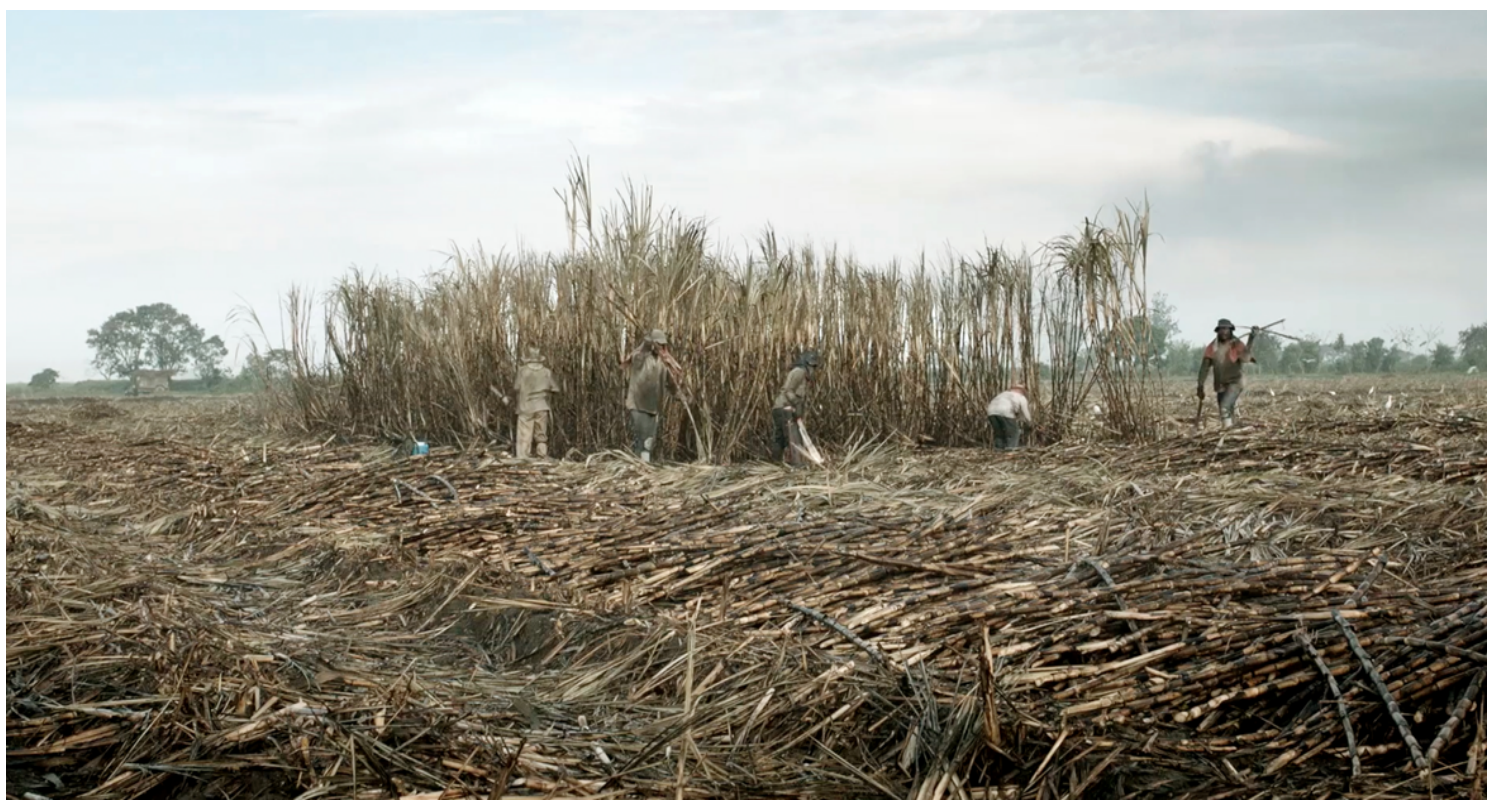

Figura 5. Anti-paisaje donde las vidas de los campesinos y las cañas son segadas.

El gesto de filmar puertas y ventanas y de articular el adentro y el afuera de la casa está presente en toda la película. La toma del humo y el fuego quemando las cañas es sucedida por una serie de tomas con cámara estática de los espacios interiores de la casa. Estas tomas retratan distintas estancias con las ventanas abiertas, que generan un efecto contraluz que oscurece la casa y parece hacer alusión a las sombras que se expanden sobre la vida privada de quienes la habitan. En la lucha entre la tierra y la sombra, Alicia y Gerardo deciden no desplazarse, pero aunque ellos permanezcan quietos, las fronteras se mueven bajo sus pies. Bajo la expansión y la devastación causadas por el extractivismo, la vida de los territorios socio-ecológicos, y la de los campesinos vinculados con estos, dejan de ser protegidos. Desde una perspectiva biopolítica, ellos están por fuera del límite que "marca el derecho a tener derechos" (Arendt, 1968, p. 296).

La lentitud que caracteriza la película es propia del modo de operar del arruinamiento y la violencia lenta, que hacen parte de la trama de la película y causan el desplazamiento de los campesinos y el desplazamiento sin movimiento de la pérdida de la tierra y el exterminio de sus agentes naturales. En Imperial Debris. On Ruins and Ruination, Laura Ann Stoler define el arruinamiento como un lento y continuo proceso de degradación y violencia (2013, p. 2). La autora señala que arruinar es "infligir o imponer un desastre de dimensiones irreparables, destruir la agencia, reducir a un estado de pobreza, desmoralizar completamente" (p. 9). ${ }^{9}$ Los tres niveles en los que opera el arruinamiento son resumidos por Stoler: "el arruinamiento es un acto que se perpetua, una condición a la que uno está sujeto, y una causa de pérdida" (p. 9). ${ }^{10}$ Estos elementos son identificables en la

\footnotetext{
9 "To inflict or bring great and irretrievable disaster upon, to destroy agency, to reduce to a state of poverty, to demoralize completely."

10 "Ruination is an act perpetrated, a condition to which one is subject, and a cause of loss."
} 
serie de precariedades que viven los personajes, la enfermedad desconocida que le quita a Gerardo su agencia, o el ambiente de desastre y devastación de los territorios. Así, esta violencia se hace tangible en la degradación de ciertos espacios ecológicos que Stoler llama "rastros de violencia distribuidos espacialmente de forma deliberada" (p. 22) o "heridas que hablan" (p. 23).

\section{El sueño del caballo y el recuerdo de otro paisaje}

Desde el comienzo, la película introduce el anti-paisaje donde ocurre la violencia lenta y el arruinamiento, junto con los agentes que la causan y la sufren. En la primera toma del film la luz natural ilumina un paisaje en tono alto. Vemos unas hojas de caña en primer plano y casi sentimos su superficie lisa que acentúa el efecto cortante de la claridad. Asimismo, se nos muestra un camino de tierra que atraviesa los cañaverales. Tras unos segundos empieza a distinguirse una mancha en el fondo del paisaje. Se trata de Alfonso que viene por el camino con una maleta (símbolo de su viaje y desplazamiento). Mientras Alfonso avanza aparece tras él un camión que lo obliga a hacerse a un lado del camino. A través de un sonido extradiegético cada vez más fuerte, los espectadores experimentamos cómo se acerca un camión gigante, con al menos cinco vagones de carga y pasa amenazadoramente rápido por la carretera, dejando una nube de polvo y sombra a su paso. Alfonso debe esperar un rato, escondido entre los cañaverales, a que se disipe la sombra del "progreso" para tomar el camino de nuevo. En esta primera escena de la película se identifica el camión como uno de los agentes del desarrollo extractivista que literalmente margina y hace desplazarse al campesino.

El film nos permite percibir el encarcelamiento del paisaje o la creación de un anti-paisaje ${ }^{11}$ que consiste en el exterminio de formas de vida sostenibles con la lógica de la esclavitud vegetal y la explotación humana y medioambiental. Así describe Nixon este tipo de construcciones políticas de paisajes según los intereses corporativos, militares y estatales en juego:

En las guerras por los recursos globales, el "ambientalismo de los pobres" se desencadena cuando se impone por la fuerza un paisaje oficial sobre uno vernáculo o nativo. Un paisaje nativo está formado por mapas afectivos, por texturas históricas que las comunidades han diseñado durante generaciones, mapas repletos de nombres y rutas, mapas vivos con características ecológicas y geológicas significativas. Un paisaje vernáculo, aunque no es ni monolítico ni definitivo, es parte integral de la dinámica socioambiental de la comunidad en vez de ser un lugar totalmente exteriorizado, tratado como si estuviera ahí fuera, como un recurso separado y no renovable. Por el contrario, un paisaje oficial, ya sea gubernamental, de una ONG, corporativo o alguna combinación de ellos, es típicamente ajeno a los mapas recién mencionados. A diferencia de estos, escribe la tierra de una manera burocrática, externalizante e impulsada por la extracción que a menudo es despiadadamente instrumental. (Nixon, 2011, p. 17) ${ }^{12}$

\footnotetext{
${ }^{11}$ Agradezco a Jorge Marcone sugerirme este término.

12 "In the global resource wars, the environmentalism of the poor is frequently triggered when an
} 
Acevedo transmite las condiciones que generaron el desplazamiento de Alfonso y sus causas a partir de un sueño del personaje. El sueño del Alfonso empieza con una imagen de sí mismo durmiendo. Como es usual en las escenas filmadas en el interior de la casa, las ventanas están cerradas y la casa está a oscuras. Mientras la cámara filma a Alfonso durmiendo, escuchamos el sonido extradiegético de los cascos de un caballo trotando sobre el piso. El sonido nos recuerda a una fotografía de un caballo que Alfonso encuentra por casualidad mientras limpia la casa en las primeras escenas de la película y se detiene a observar con afecto durante varios segundos. Alfonso se levanta de la cama y pasa de una habitación a otra. A través de un plano dorsal o semiobjetivo, vemos la espalda del personaje y nos adentramos con él en la escena.

Cuando llega al cuarto de su hijo Gerardo, Alfonso encuentra el caballo encerrado, dando vueltas en círculos, inquieto en la habitación vacía. Las ventanas están abiertas, la luz natural entra desde las ventanas a través de las cortinas translúcidas que nos permiten sentir la textura de la luz. Las ventanas abiertas sugieren que lo que pasa fuera de la casa afecta lo que está adentro, logra entrar en ella. Alfonso se acerca al caballo, intenta apaciguarlo, lo consiente, y lo deja salir de la habitación. El caballo empieza a recorrer los corredores de la casa que parecen un laberinto, finalmente encuentra la puerta, y tan pronto se encuentra en el exterior de la casa, sale corriendo hacia los cañaverales. En su camino de huida de los cañaverales iluminados, el caballo pasa junto a Alicia y Gerardo que yace acostado en la cama al lado del samán. Los dos permanecen inmóviles, expuestos a una luz que lastima, conseguida con la técnica cinematográfica de la sobreexposición. Este caballo es la memoria de sí mismo que guarda Alfonso, es quien era antes de irse. A través del sueño, Alfonso entra en un contacto háptico con el caballo que representa "la memoria corporizada de su propia reacción frente a la situación que lo rodea" (Marks, 2000, p. 157). Esto es, el encierro del caballo en la casa rodeada de cañaverales altos como rejas muestra los motivos que llevaron a Alfonso a desplazarse.

Los movimientos de Alfonso, las maneras en las que recorre el paisaje y lo lee con sus pasos, y las formas en las que interactúa con él son los indicios hápticos que llevan al espectador a intuir que el paisaje anterior era distinto y que algo anda mal en el nuevo anti-paisaje. Solo él y las otras personas que han habitado en y con el territorio lo conocen como a un miembro de la familia con el que han convivido, y son los primeros que se dan cuenta de la violencia ambiental y sufren sus consecuencias. La identidad de este personaje tiene que ver con su relación con la tierra y el haberse marchado de ella lo deja en un estado de desposesión que

official landscape is forcibly imposed on a vernacular one. A vernacular landscape is shaped by the affective, historically textured maps that communities have devised over generations, maps replete with names and routes, maps alive to significant ecological and surface geological features. A vernacular landscape, although neither monolithic nor undisputed is integral to the socioenvironmental dynamics of community rather than being wholly externalized, treated as out there, as separate nonrenewable resource. By contrast, an official landscape, whether governmental, NGO, corporate, or some combination of those, is typically oblivious to such earlier maps: instead it writes the land in a bureaucratic, externalizing, and extraction-driven manner that is often pitilessly instrumental". 
Acevedo explora a través de la soledad del personaje.

El samán al que Alfonso constantemente vuelve en la película es uno de los pocos agentes que queda de la comunidad socio-ecológica que había antes del monocultivo y bajo su sombra los personajes reviven un pasado donde tenían más bienestar y una relación más sostenible con el territorio. Alfonso observa el árbol largamente, le enseña a su nieto a hacer casas de pájaros y a comunicarse con ellos con distintos tipos de silbidos. Bajo la sombra del samán, Alfonso y Alicia consiguen comunicarse luego de sus diferencias y separación. Este árbol muestra que el monocultivo es una utopía que tiene grietas y no consigue imponerse del todo. Y también da cuenta de la capacidad de los personajes de sentipensar con el territorio. Con este término Arturo Escobar se refiere a la creación de territorios socio-ecológicos por parte de comunidades campesinas por medio de una "apropiación efectiva [y afectiva] mediante prácticas culturales, agrícolas, ecológicas, económicas o rituales” (Escobar, 2014, p. 90). Esta apropiación es un gesto ontológico, en el que las comunidades instauran una forma de entender y hacer la política según su experiencia de mundo (p. 90) y es justamente esto lo que pierde la familia con la imposición del monocultivo.

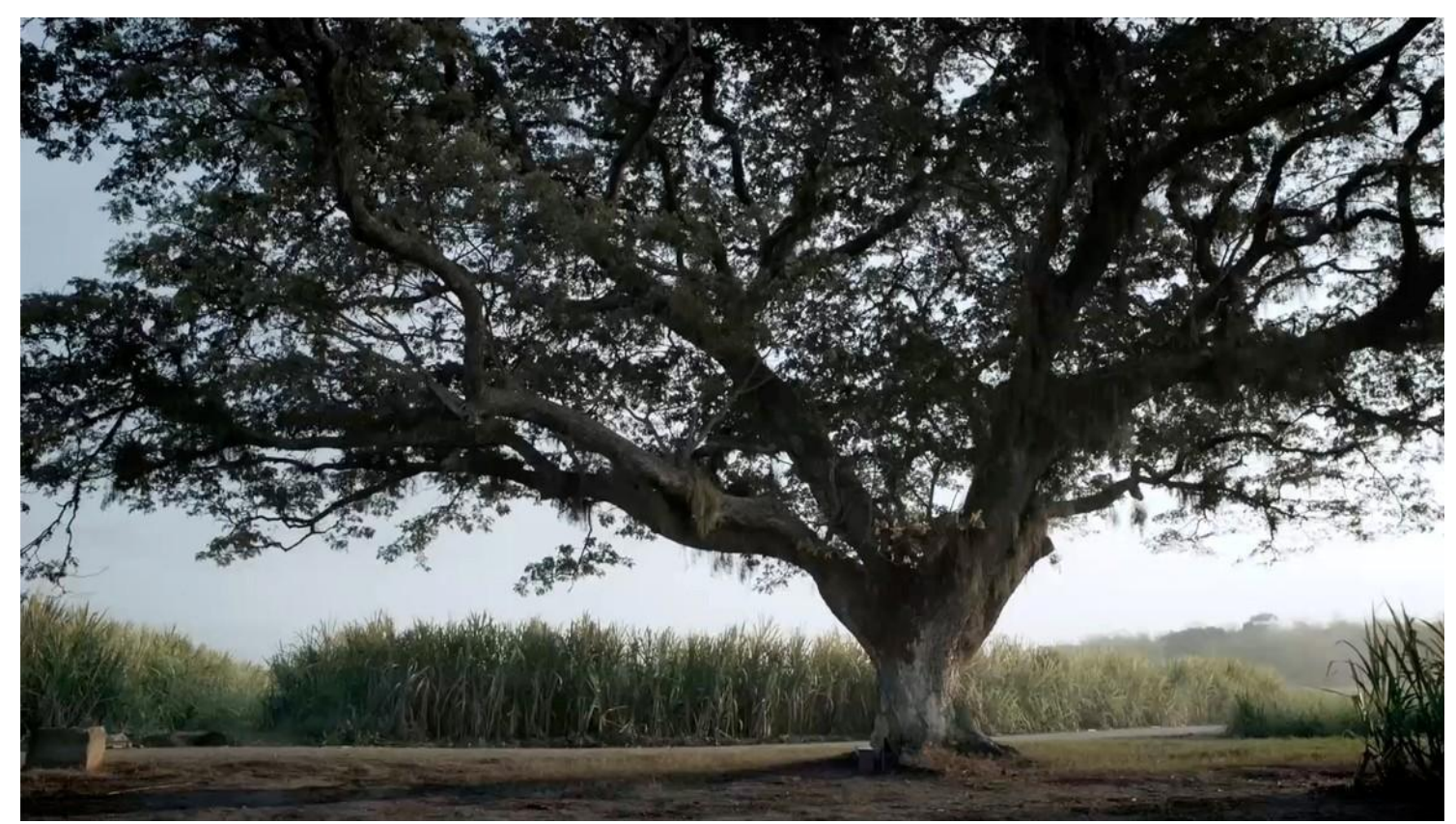

Figura 6. El samán y las cañas

El vínculo afectivo que Alfonso tiene con el territorio y los actantes no humanos (cultivos, pájaros, el samán, el caballo), que se actualizaba a partir de su trabajo en/con ellos, parece la condición de posibilidad para que el personaje pueda generar vínculos con los otros miembros de su familia. Eso se ve en las palabras que le dice a Alicia bajo la sombra del samán: "no sé si valió la pena haberme marchado. Todos los días pensaba que no los iba a volver a ver, ni a pisar mi tierrita." Y en otro momento dice: "yo no me podría quedarme aquí a ver cómo se acababa todo esto ante mis ojos". Así, este personaje decide marcharse para salvar su vida a pesar de que los otros miembros de su familia no estén de acuerdo. 
En este diálogo y en el enfrentamiento y la separación entre Alfonso y Alicia se ven los efectos de la violencia lenta sobre la vida privada de los personajes campesinos de la película. Alicia tiene un vínculo similar con la tierra, pero su forma de resistir consiste en quedarse a defender el territorio y negarse a vender la tierra a la multinacional azucarera. Alicia resiste hasta el punto de que su casa es la única que queda en pie en el cañaveral. Sin embargo, paga un precio muy alto con la muerte de su hijo.

La situación de precariedad hace que los diferentes miembros de la familia tengan una ruptura con su identidad tradicional y ensayen distintas alternativas sobre cómo resistir al desplazamiento. Estas distintas posiciones están influidas también por elementos como el género, ${ }^{13}$ y las distintas generaciones a las que pertenecen los integrantes de la familia. La película complejiza las representaciones de los campesinos que circulan en los discursos públicos en la medida que muestra que no hay una esencia cristalizada en una identidad fija que corresponde a "lo campesino", sino que sus procesos de formación de identidad son más complejos, heterogéneos e incluyen transformaciones. Asimismo, sus relaciones con la tierra, a pesar de que se basen en conocimientos ancestrales son variables y están en constante transformación.

\section{Precariedad, agencia y encuadre}

Dos de las nociones de precariedad que proponen Burucúa y Stinisky (2018) para articular el cine contemporáneo en las Américas dan cuenta de las relaciones entre los personajes de la película y la audiencia que promueve La tierra y la sombra. La primera de ellas se refiere a la precariedad laboral que, como señala Bourdieu afecta no solamente las condiciones de trabajo de las personas, sino sus vidas privadas y públicas, puesto que: "la precariedad es parte de un nuevo tipo de dominación, basado en la instauración de un estado de inseguridad generalizado y permanente, que tiene como objetivo obligar a los trabajadores a someterse a la aceptación de la explotación" (Bourdieu, 1997, p. 97; Burucúa y Stinisky, 2018, p. 4). La película nos pone en contacto con las distintas manifestaciones de esta precariedad, como el hecho de que la familia no tenga otras formas de subsistencia que no sea trabajar en el monocultivo que los enferma y mata. Otro ejemplo es cuando Esperanza dice que en: "esta [...] finca [...] uno trabaja y trabaja y no saca nada". A pesar de que no todas las precariedades laborales operan de la misma forma ni generan desplazamiento, la experiencia de la precariedad laboral es traducible a una preocupación de una variedad de movimientos sociales en América Latina, en especial a partir de las crisis generadas por el neoliberalismo desde los años 1980 y 1990. En este sentido, es probable que la audiencia haya tenido alguna experiencia similar, en algún grado, o haya estado en contacto con

\footnotetext{
${ }^{13}$ Alfonso y Alicia ensayan algunas inversiones de roles de género durante la película. Cuando Alfonso regresa a su territorio doce años después, su rol es cuidar a su hijo Gerardo, limpiar la casa y hacer los oficios domésticos mientras las mujeres, Alicia y Esperanza, trabajan en los cañaverales. Las diferencias que genera el desplazamiento o la amenaza del desplazamiento no se limitan a la inversión de roles de género, sino que dentro de los géneros también se reflexiona sobre qué posición asumir y qué decisiones tomar frente a la situación y la vida íntima.
} 
alguien en esta situación y estas experiencias se hacen relevantes para la recepción háptica de la película, para sentir su advertencia en la propia piel y reflexionar sobre las conexiones entre las distintas precariedades.

La segunda noción de precariedad promovida por las técnicas hápticas de la película, o que promueve el contacto entre los espectadores y los testimonios de los personajes, es la que desarrolla Judith Butler (2004) a partir de la noción de pérdida. En la película, la pérdida asociada a la precariedad está presente de varias maneras. Algunos ejemplos son la pérdida de Gerardo a partir de su muerte, la pérdida de la tierra, la pérdida del paisaje vernacular sostenible por la imposición del monocultivo, la pérdida del vínculo amoroso entre Alfonso y Alicia, la pérdida del caballo. No obstante, los personajes hacen alianzas y ejercen sus agencias de distintas maneras, a pesar de que sean frágiles. Como señala María Helena Rueda, el regreso de Alfonso permite un contraste entre el presente y el pasado marcados por la pérdida (Rueda citada en Burucúa y Stinisky, 2018, p. 157). Esta constante alerta sobre la necesidad de creación de nuevas relaciones políticas en aras de un futuro distinto en el territorio que permita la supervivencia de sus agentes humanos y no humanos. La película, sigue Rueda, se propone denunciar esta precariedad haciéndola visible, expone las heridas y las hace hablar de las causas que las generaron, promoviendo un compromiso ético y político de los espectadores con estas realidades que se expanden como una sombra sobre las distintas comunidades y muestran sus interdependencias.

Para Butler (2004) la precariedad es una experiencia relacionada con la pérdida común que muestra la vulnerabilidad compartida, la interdependencia y promueve la agencia o la liberación de nuevas fuerzas creativas de acción comunitaria a través de procesos de duelo (p.20). Que hayamos perdido a alguien o algo importante para nosotros, o que tengamos la posibilidad de perderlo, sigue Butler, presupone que hemos tenido algo y que hemos luchado por mantener nuestra relación de amor o de deseo con lo que hemos perdido (ibid.). En la pérdida y en el duelo posterior a la pérdida salen a la luz los vínculos que tenemos con los otros y con el mundo, y esto nos da la posibilidad de construir nuevos vínculos. Así, la pérdida es uno de los lazos que forman un "nosotros" que es la base de una comunidad política (Butler, 2004, p. 22). Como lo veo, la película se propone hacer estas heridas visibles más allá del universo fílmico, valiéndose de sus estatus de testimonio susceptible de memoria histórica, que abarca la memoria ambiental. Además, al relacionar la violencia política con los problemas ambientales muestra el papel clave de los agentes y territorios socio-ecológicos en la reconciliación que busca el posconflicto colombiano. Así, las fuerzas creativas que libera este duelo comprenden imaginar "nuevos" sujetos políticos o la configuración de comunidades políticas que incluyen agentes no humanos como el caballo, el samán y las cañas.

La acción de la película de enmarcar y encuadrar estos agentes socio-ecológicos y los peligros ambientales que los acechan es un gesto político que los introduce en el ámbito de la esfera pública y con ellos llama la atención sobre la necesidad de cuidar sus vidas. La película se opone a la invisibilización y marginación de los derechos humanos y ambientales que sufren los campesinos y los otros agentes no humanos en este territorio del Valle del Cauca al mostrar en 
primer plano los peligros que los acechan. Esto se ve, por ejemplo, en la escena en la que las cañas intentan resistir a su exterminio, pero son quemadas y obligadas a generar ceniza y contaminación bajo la lógica de la esclavitud vegetal que promueve el monocultivo con fines extractivistas. Como señala Butler en sintonía con Hannah Arendt, la esfera pública se compone de una contienda donde coexisten la visibilidad y la invisibilidad de distintos agentes y comunidades, y la visibilidad es uno de los criterios para determinar qué vidas se protegen y qué muertes se lamentan y evitan (p. xvi).

La película La tierra y la sombra aporta a la comprensión del desplazamiento y la violencia lenta en la cultura colombiana y latinoamericana, porque reactualiza el debate del extractivismo a través del lenguaje fílmico del cine háptico. No percibir la violencia lenta de carácter ambiental que señala la película es un problema político fundamental para Colombia, porque esta violencia es una de las causas estructurales del conflicto armado y político del país. Así, la película hace visibles y sitúa en la esfera pública una serie de pérdidas, precariedades y arruinamientos que comportan violencias lentas políticas y ambientales que causan desplazamiento forzado. Además del desplazamiento de personas, aporto una segunda definición de desplazamiento que no implica el viaje de personas, sino el movimiento de fronteras bajo sus pies. Este segundo tipo de desplazamiento consiste en la pérdida de la tierra, y las formas de vida sostenibles en las que participan agentes a partir de la imposición del monocultivo.

El film es un dispositivo multisensorial que alerta nuestra memoria corporal y nos permite percibir cómo la violencia lenta corta las texturas y redes que sostienen la vida colectiva e individual dentro y fuera de la película. La circulación de estas imágenes en la esfera pública promueve preguntas sobre las responsabilidades de los testigos de la violencia política y su agencia que se desenvuelve fuera de la dicotomía víctima-victimario. Las imágenes hápticas de la película permiten percibir o (re)presentan los cuerpos y agentes no humanos que también se ven afectados por esta violencia y reclaman un espacio en nuestras comunidades políticas. Tal vez en compañía de ellos, o sintiendo su cercanía por medio de la pantalla, podamos construir un futuro con otras imágenes, imaginar un futuro distinto. 


\section{Referencias}

Arendt, H. (1968). The Origins of Totalitarianism. Nueva York,United States: Harcourt.

Burucúa, C., Sitnisky, C., y Farrell, M. L. (2018). The Precariousness in the Cinemas of the Americas. Modern Languages \& Literature Faculty Book Gallery, (15). Recuperado de: https://digitalcommons.fairfield.edu/modernlanguagesandliterature-books $\not 15$

Bourdieu, P. (1997). La précarité est aujourd'hui partout. Contre-feux (pp. 95-101).Grenoble: Les Éditions Raisons d'agir.

Butler, J. (2004). Precarious Life. London and New York: Verso.

Comisión de la Verdad, La Asociación Nacional de Usuarios Campesinos (ANUC). (2020). Informe: Resistencia y persistencia.

Escobar, A. (2014). Sentipensar con la tierra. Nuevas lecturas sobre desarrollo, territorio y diferencia. Medellín, Colombia: Ediciones UNAULA.

Forero, J., Pérez Nieto, P., Bustamante, D. (productores) y Acevedo, C. (director). (2015). La tierra y la sombra [Cinta cinematográfica]. Colombia: Burning Blue.

Malagón, C. (2020). Post-Conflict Visual Ecologies: Violence and Slow Violence in Chocó by Jhonny Hendrix Hinestroza and La tierra y la sombra by César Augusto Acevedo. Revista de Estudios Colombianos, (55), pp. 30-41.

Marks, L.U. (2000). The Skin of the Film. Intercultural Cinema, Embodinmnet and the Senses. Durham and London, United States and United Kingdom: Duke University Press.

Martínez, M. A. (2020). Radiografía de la violencia contra los líderes asesinados en Colombia. ONG Idiepaz: Instituto de Estudios para el desarrollo y la paz. Recuperado de:

http://www.indepaz.org.co/radiografia-de-la-violencia-contra-los-lideres-a sesinados-en-colombia/\#: : text=En\%20el\%20pa\%C3\%ADs\%20el\%20ho micidio, $1 \%$ C3\%ADderesas $\% 20$ defensores $\% 20$ de $\% 20$ derechos $\% 20$ humano $\underline{\text { S. }}$

Nixon, R. (2011). Slow Violence and the Environmentalism of the Poor. Cambridge and London, United States and United Kingdom: Harvard University Press.

Ospina, M. (2017). Natural Plots: The Rural Turn in Contemporary Colombian Cinema. En Fanta Castro, A., Herrero-Olaizola, A. y Rutter-Jensen, Ch. (Eds.), Territories of Conflict (pp.248-266). Rochester, United States: University of 
Rochester Press.

Ospina, M. (2020). Narrativa, artes visuales y fílmicas a la luz de los Acuerdos de Paz en Colombia. Revista de Estudios Colombianos, (55) pp.5-8.

Stoler, A. L. (2013). Imperial Debris. On Ruins and Ruination. Durham and London, United States and United Kingdom: Duke University Press. 